\title{
Neuropsychological and behavioral functioning in children with and without obstructive sleep apnea referred for tonsillectomy
}

\author{
BRUNO GIORDANI, ${ }^{1}$ ELISE K. HODGES, ${ }^{1}$ KENNETH E. GUIRE, ${ }^{2}$ DEBORAH L. RUZICKA, ${ }^{3}$ \\ JAMES E. DILLON, ${ }^{4}$ ROBERT A. WEATHERLY, ${ }^{5}$ SUSAN L. GARETZ, ${ }^{5}$ AND \\ RONALD D. CHERVIN ${ }^{3}$ \\ ${ }^{1}$ Neuropsychology Section, Department of Psychiatry, University of Michigan, Ann Arbor, Michigan \\ ${ }^{2}$ Biostatics Department, School of Public Health, University of Michigan, Ann Arbor, Michigan \\ ${ }^{3}$ Sleep Medicine, Neurology Department, University of Michigan, Ann Arbor, Michigan \\ ${ }^{4} \mathrm{MDCHC} /$ Corrections and Division of Child and Adolescent Psychiatry, Department of Psychiatry, University of Michigan, \\ Ann Arbor, Michigan \\ ${ }^{5}$ Otorhinolaryngology Department, University of Michigan, Ann Arbor, Michigan
}

(Received April 20, 2007; Final Revision March 16, 2008; Accepted March 17, 2008)

\begin{abstract}
Adenotonsillectomy (AT) is among the most common pediatric surgical procedures and is performed as often for obstructive sleep apnea (OSA) as for recurrent tonsillitis. This study compared behavioral, cognitive, and sleep measures in 27 healthy control children recruited from a university hospital-based pediatric general surgery clinic with 40 children who had OSA (AT/OSA+) and 27 children who did not have OSA (AT/OSA-) scheduled for AT. Parental ratings of behavior, sleep problems, and snoring, along with specific cognitive measures (i.e., short-term attention, visuospatial problem solving, memory, arithmetic) reflected greater difficulties for AT children compared with controls. Differences between the AT/OSA - and control groups were larger and more consistent across test measures than were those between the AT/OSA + and control groups. The fact that worse outcomes were not clearly demonstrated for the AT/OSA + group compared with the other groups was not expected based on existing literature. This counterintuitive finding may reflect a combination of factors, including age, daytime sleepiness, features of sleep-disordered breathing too subtle to show on standard polysomnography, and academic or environmental factors not collected in this study. These results underscore the importance of applying more sophisticated methodologies to better understand the salient pathophysiology of childhood sleep-disordered breathing. (JINS, 2008, 14, 571-581.)
\end{abstract}

Keywords: Polysomnography, Neuropsychology, Sleep-disordered breathing, Adenotonsillectomy, Tonsillitis, Snoring

\section{INTRODUCTION}

Adenotonsillectomy (AT) is one of the most frequent pediatric surgical procedures. Performed mainly for recurrent pharyngitis in the past, AT is now used approximately as often to treat childhood sleep-disordered breathing (SDB; Marcus and Loughlin, 1996; Weatherly et al., 2003). SDB is a general term that can refer to children with upper

Correspondence and reprint requests to: Bruno Giordani, Neuropsychology Section, Department of Psychiatry, University of Michigan, Suite C, 2101 Commonwealth Blvd., Ann Arbor, MI 48105-0716. E-mail: giordani@umich.edu airway resistance syndrome or habitual snoring that disturbs sleep, as well as children with obstructive sleep apnea (OSA). Earlier investigations reported that up to $18 \%$ of children referred for AT have SDB (Hibbert, 1981; Rosenfeld and Green, 1990; Stradling et al., 1990), but more recent studies suggest this figure is $40 \%$ or higher (Weatherly et al., 2004). For many children, SDB is associated with significant daytime cognitive and behavioral symptoms. Alterations in blood gases and cortisol levels accompanying SDB may influence behavior and cognition (Beebe and Gozal, 2002; Zoccoli et al., 2002) and may selectively affect key regions in the developing brain such as the 
bhippocampus and prefrontal cortex (PFC; Bartlett et al., 2004; Beebe and Gozal, 2002; Halbower et al., 2006; Morrell et al., 2004).

Consistent with the possibility of academic difficulties in school-aged children with SDB, Chervin and colleagues (2003) found that SDB symptoms in urban school children were associated with teacher-reported academic difficulties, and Urschitz et al. (2003) found that children with the SDB marker, intermittent hypoxia, were more than twice as likely to have poor performance in academic subjects (Urschitz et al., 2003). Beebe (2006) recently comprehensively reviewed the evidence related to cognitive and behavioral morbidity associated with childhood SDB. He noted that although school reports and academic ratings by parents consistently suggest difficulties in this area for children with SDB symptoms, studies that have used formal, academic testing have not found this to be the case (Emancipator et al., 2006; Kaemingk et al., 2003). For the most part, studies incorporating neuropsychological testing find lowered performance in measures of attention, executive functioning, and memory to some degree, while standardized tests of language functioning, shortterm attention, and nearly all aspects of visual perception fail to suggest deficits associated with SDB (Beebe, 2006).

Investigations have reported a significant relationship between SDB and behavioral disturbance. For example, parent-reported snoring is associated with parent-identified symptoms of inattention and hyperactivity in clinic and community-derived samples of children (Chervin et al., 2003; Gottlieb et al., 2003). Beebe (2006) notes that among behavioral symptoms, increased behavior disturbances, such as hyperactivity, rebelliousness, and aggression, have been linked in multiple studies to children whose parents report SDB symptoms, are awaiting AT, and/or who have PSGconfirmed OSA. Findings for mood problems appear less consistent, however.

A handful of studies have specifically examined the neuropsychological functioning of children before AT. Most of these studies suggest that children scheduled for AT may demonstrate lower scores in general intellect (Kennedy et al., 2004; Montgomery-Downs et al., 2005), visual attention (Archbold et al., 2004; Avior et al., 2004), and visual-based reasoning and problem solving (Archbold et al., 2004; Friedman et al., 2003). Owens and colleagues (2000) suggested the possibility of a mixed pattern of problems: AT children with mild SDB having attention difficulties and executive deficits; AT children with more severe SDB, having more evidence of memory problems. A few studies do not support a picture of clear difficulties in children scheduled for AT. For example, Ali and co-workers (1996) compared the pre-AT performance of 12 children with OSA to that of 11 snoring children without OSA and 10 non-AT surgical controls. The groups did not differ on computerized or paper-and-pencil measures of sustained attention and impulsivity. The groups also showed no baseline differences on parent and teacher behavior rating scales. Sim- ilarly, in a study of a larger sample of children, Mitchell and Kelly (2005) used parent ratings to preoperatively evaluate 52 children ranging widely in age ( 2.5 years to 18 years). No scores were within a clinically significant range.

Most of the studies cited above establish a possible link between parent-reported sleep and cognitive and behavioral morbidities, although not necessarily with objective measures of either sleep or neuropsychological functioning. Conflicting findings have been reported in the few studies that have included objective methodologies. In a study that examined objective measures of SDB and neuropsychological functioning, O'Brien et al. (2004a) found that children with SDB had lower scores on measures of general cognition, visual spatial ability, attention, language, and executive functioning compared with children without SDB. In contrast, Beebe and colleagues (2004) did not find a significant relationship between OSA and neuropsychological morbidity in children, although trends were observed that suggested the possibility that OSA severity was associated with greater difficulties in visual attention and verbal fluency.

The present report takes advantage of the relatively large dataset from the Washtenaw Adenotonsillectomy Cohort (Chervin et al., 2006). We have previously shown that children in this cohort scheduled for AT as compared with those scheduled for unrelated surgical care were reported by their parents to be more hyperactive, were more sleepy on the Multiple Sleep latency Test, were more likely to have attention-deficit/hyperactivity disorder on psychiatric interview, and demonstrated a lower score on a cognitiveattention index derived from a combination of scores on computerized and paper-and-pencil tests of attention. When this AT group was divided into those with and without OSA, both of the tonsillectomy groups were found to have a lower summary cognitive-attention index score and a higher parental index of hyperactivity as compared with controls.

In this study, we more specifically address baseline neuropsychological evaluation of these same participants, which was beyond the scope of the previous study that summarized the overall project and included only the summary measure of attention. Consistent with the review by Beebe (2006), we hypothesized that AT children would show specific areas of cognitive impairment as compared with controls, in particular, on tasks reflecting sustained attention and executive functioning and on parental reports of hyperactivity and externalizing difficulties. Furthermore, we predicted that the AT children diagnosed with OSA would demonstrate the most severe difficulties in these areas. As Beebe (2006) has noted, findings for many other domains of cognitive functioning have been mixed or involved studies that precluded firm conclusions due to insufficient power or other mitigating factors. This study includes a larger number of participants relative to previous studies and provides polysomnography-based diagnosis of OSA for all subjects with the hope of obtaining more definitive findings. 


\section{METHOD}

\section{Participants}

Participants included 79 children (41 boys, 38 girls), referred for AT (age range: 5 to 12 years, 11 months) from otolaryngology practices in the suburbs of a large Midwestern city, as originally described in Chervin et al. (2006). Of these children, 71 (91\%) were thought by their otolaryngologist to have nocturnal upper airway obstruction (Chervin et al., 2006). In addition, 27 control participants (19 boys, 8 girls, same age range) were recruited from a university hospital-based pediatric general surgery clinic. Additional details on demographics and medical features of these patients have been described elsewhere (Chervin et al., 2006). Exclusion criteria included neurological comorbidity that could have affected cognitive or behavioral functioning, craniofacial anomalies that could affect breathing, necessity of a polysomnogram for clinical purposes that could suggest other conditions besides OSA, and prior treatment for SDB. Parents of the one child treated with a stimulant (Concerta) agreed to discontinue use 10 days before study. Control subjects also were excluded for a history of large tonsils, frequent throat infections, or previous adenoidectomy or tonsillectomy to reduce these potentially mitigating factors in comparisons of the children scheduled for AT versus controls.

Polysomnography was used to diagnose OSA in all children (see below). One of the control participants was found to have OSA and was excluded from the study, leaving 26 children in the healthy control comparison group. Among the AT children, 40 children (18 boys, 22 girls) were found to have OSA (AT/OSA+ group) with ages ranging from 5.25 to 12.46 years. There were 28 AT children (19 boys, 19 girls) found to not have OSA (AT/OSA - group) with ages ranging from 5.49 to 12.11 years. The groups did not differ in terms of gender $\left(\chi^{2}=2.40\right)$, race $\left(\chi^{2}=4.27\right)$, or percentage of children in special education $\left(\chi^{2}=2.08\right)$ or receiving other special services $\left(\chi^{2}=2.08\right)$, although the $\mathrm{AT} / \mathrm{OSA}+$ group was significantly younger than the control group (Table 1) and, as would be expected based on age, had lower education. The two AT groups were compared across various indications for surgery based on their referrals. No group differences were noted, however, for chronic tonsillitis $\left(\chi^{2}=2.10\right)$, obstructive breathing during the day $\left(\chi^{2}=0.57\right)$ or night $\left(\chi^{2}=0.21\right)$, or other indications for surgery $\left(\chi^{2}=0.84\right)$. Covarying the analyses reported in this study for age did not appreciably change the major intergroup comparisons.

\section{Procedure}

Before beginning study evaluations, each child provided assent and a parent provided consent as approved by the Institutional Review Boards of the University of Michigan Medical School. Children were prepared for their sleep study, using their usual bedtime as a guide. Overnight, each child

Table 1. Means and standard deviations for demographic and sleep-related variables

\begin{tabular}{|c|c|c|c|c|c|c|}
\hline & \multicolumn{4}{|c|}{ Group effect } & \multicolumn{2}{|c|}{ Comparison to controls } \\
\hline & $\begin{array}{c}\mathrm{AT} / \mathrm{OSA}+ \\
(n=40)\end{array}$ & $\begin{array}{c}\mathrm{AT} / \mathrm{OSA}- \\
(n=38)\end{array}$ & $\begin{array}{l}\text { Control } \\
(n=26)\end{array}$ & $F$ & $\mathrm{AT} / \mathrm{OSA}+$ & AT/OSA- \\
\hline Age & $\begin{array}{c}7.83 \\
(1.80)^{\mathrm{a}}\end{array}$ & $\begin{array}{c}8.43 \\
(1.77)\end{array}$ & $\begin{array}{c}9.15 \\
(1.97)\end{array}$ & $4.12 *$ & $*$ & \\
\hline Education & $\begin{array}{c}2.08 \\
(1.85)\end{array}$ & $\begin{array}{c}2.58 \\
(1.70)\end{array}$ & $\begin{array}{c}3.35 \\
(1.98)\end{array}$ & $3.81 *$ & $*$ & \\
\hline SES & $\begin{array}{c}2.43 \\
(1.03)\end{array}$ & $\begin{array}{c}2.87 \\
(0.99)\end{array}$ & $\begin{array}{c}2.50 \\
(0.71)\end{array}$ & 2.35 & & \\
\hline $\mathrm{OAI}^{\mathrm{b}}$ & $\begin{array}{c}5.56 \\
(8.05)\end{array}$ & $\begin{array}{c}0.14 \\
(0.15)\end{array}$ & $\begin{array}{c}0.07 \\
(0.14)\end{array}$ & $82.58 * * *$ & $* * *$ & \\
\hline MSLT $^{\mathrm{c}}$ & $\begin{array}{l}15.61 \\
(3.19)\end{array}$ & $\begin{array}{l}16.77 \\
(3.20)\end{array}$ & $\begin{array}{l}17.47 \\
(3.21)\end{array}$ & $2.88^{\mathrm{d}}$ & $*$ & \\
\hline $\mathrm{PSQ}^{\mathrm{e}}$ Snoring & $\begin{array}{c}0.87 \\
(0.37)\end{array}$ & $\begin{array}{l}0.57 \\
(.38)\end{array}$ & $\begin{array}{c}0.07 \\
(0.45)\end{array}$ & $91.34 * *$ & $* * *$ & $* * *$ \\
\hline $\mathrm{PSQ}^{\mathrm{e}}$ Sleepiness & $\begin{array}{c}0.36 \\
(0.51)\end{array}$ & $\begin{array}{c}0.31 \\
(0.52)\end{array}$ & $\begin{array}{c}0.13 \\
(0.63)\end{array}$ & $4.58 * *$ & $* *$ & $*$ \\
\hline
\end{tabular}

${ }^{\mathrm{a} N u m b e r s ~ i n ~ p a r e n t h e s e s ~ r e p r e s e n t ~ s t a n d a r d ~ d e v i a t i o n s . ~}$

${ }^{\mathrm{b}}$ Obstructive Apnea Index (OAI) analyses completed on log data due to skewed distribution, but raw data presented for clarity.

${ }^{\mathrm{c}}$ Multiple Sleep Latency Test.

${ }^{\mathrm{d}}$ Trend, $p=.06$.

ePediatric Sleep Questionnaire (PSQ) subscale.

$* p<.05$.

$* * p<.01$.

$* * * p<.001$. 
underwent a polysomnogram (PSG) and the following day a Multiple Sleep Latency Test (MSLT), with neuropsychological assessment between MSLT naps.

\section{Polysomnography}

All participants underwent overnight digital PSG using pediatric methods described in detail previously (see Chervin et al., 2006, for descriptions of methodology and details of sleep studies for all children). Recordings were scored following standard rules (Rechtschaffen and Kales, 1968) by an experienced, registered technician who was unaware of the participants' clinical, demographic, or surgical status. Obstructive apneas were scored in the absence of thermocouple-monitored airflow for a minimum of two breath cycles. Central apneas unrelated to a sigh or to movement were scored if they exceeded $20 \mathrm{~s}$ or if they exceeded $10 \mathrm{~s}$ and were associated with bradycardia or oxygen desaturation $\geq 4 \%$. The AT group was split by presence or absence of OSA as determined by scores on the obstructive apnea index (OAI). Polysomnographic criteria to identify OSA are debated, in part because insufficient data have been generated to prove what levels of recorded pathology are associated with meaningful outcomes. However, one of the most commonly cited criteria is an OAI of 1 event per hour of sleep or more (Marcus et al., 1992). Although in clinical practice hypopneas are often scored and counted within an apnea/hypopnea index, definitions for hypopneas vary much more widely than those for apneas in clinical practice and research, and hypopneas have lower scoring reliability than apneas. For these reasons, we chose the most widely used criterion, based on obstructive apneas only, to define children with OSA. We chose OAI greater than or equal to 0.50 to conservatively identify that the AT/OSA - group was clearly free of any significant sleep apnea.

\section{Daytime Sleepiness}

The MSLT was used as an objective measure of daytime sleepiness. Latencies for each of four or five naps attempted at 2-hr intervals were computed as the time between lights being turned off, and the first epoch of stage 1 sleep (Carskadon et al., 1986). Sleep latency results are included (Table 1) to better describe the setting in which the children were tested. Only a trend was noted for differences between the groups, with only the AT/OSA+ comparison to controls reaching significance.

\section{Parental Ratings of Sleep Disturbance}

The Pediatric Sleep Questionnaire (PSQ) was given to parents to provide subjective assessments of the children's nocturnal and diurnal symptoms (Chervin et al., 2000, 2007). The PSQ Sleepiness and Snoring subscales were included in the analyses and clearly differentiated the AT groups from the controls (Table 1), with the sleepiness finding being more robust for the AT/OSA + group, consistent with MSLT findings.

\section{Neuropsychological Measures}

Administered neuropsychological measures are listed below grouped into domains for ease in presentation. Standard scores are reported for each test measure.

Verbal Ability included the two verbal subtests of the Wechsler Abbreviated Scale of Intelligence (WASI; The Psychological Corporation, 1999), Vocabulary and Similarities.

Visual Spatial Ability was represented by the two WASI nonverbal subtests, Block Design and Matrix Reasoning subtests.

Academic Achievement included several subtests from the Wechsler Individualized Achievement Test (WIAT; The Psychological Corporation, 1992). Verbal achievement measures were Reading, Reading Comprehension, Spelling, Listening Comprehension and Oral Expression. The arithmetic-related measures consisted of the Mathematics Reasoning and Numerical Operations subtests from the WIAT.

Short-Term Attention / Working Memory subtests were chosen from the Children's Memory Scale Attention and Concentration Index (CMS; Cohen, 1997), specifically the Numbers and Sequences subtests.

Sustained Attention was represented by two primary subscales from the Integrated Variables of Attention computerized continuous performance test (IVA; Sanford \& Turner, 1994) to measure vigilance and sustained attention (Full Scale Attention Quotient, FSAQ) and response inhibition and impulsivity (Full Scale Response Control Quotient, FSRCQ).

Verbal Learning included the Stories immediate recall and Word Pairs learning CMS subtests.

Verbal Delayed Recall was represented by the delayed recall scores from CMS Stories and Word Pairs.

Visual Learning consisted of the learning scores from the CMS Dots subtest and the immediate recall scores from the CMS Faces subtest.

Visual Delayed Recall consisted of the delayed recall scores from CMS Dots and Faces.

Executive Functioning was chosen to be the total T-score from the Children's Category Test (Boll, 1993).

Fine Motor Coordination was represented by the bihaptic trial from the Purdue Pegboard (Tiffin, 1968).

The test order for the variables presented in this study was: (1) Purdue Pegboard, (2) Children's Category Test, (3) WIAT, (4) WASI, (5) CMS, and (6) IVA. However, research assistants had significant latitude in presenting the tests based on changes in timing due to breaks for children and the MSLT procedures.

\section{Emotional and Behavioral Assessment}

Although the primary purpose of this study was to evaluate neuropsychological functioning, the Conners' Parent Rating Scale: Long Version (CPRS-R:L; Conners, 1997) was 
included to provide a parent-based approach to the measurement of child behavior. Subscale standardized T-scores were grouped and added together, a priori, according to expected conceptual relationships into three separate domains representing hyperactivity and externalizing and internalizing behaviors. These domains were submitted to confirmatory factor analyses (SAS PRINCOMP Procedure) to demonstrate their internal reliability. Each of the resultant domain correlation matrices demonstrated eigenvalues $>1$ (Hyperactivity $=3.34$, Externalizing $=1.77$, Internalizing $=1.95$ ) and percent variance accounted for ranging from $49 \%$ to $88 \%$ (Hyperactivity $=83 \%$, Externalizing $=88 \%$, and Internalizing $=49 \%$ ). Individual tests in each domain demonstrated eigenvectors on the first principle component between 0.44 and 0.70 . Higher T-scores for each resulting summary scale represent increased complaints. Subscales that were combined related to hyperactive behaviors included Hyperactivity, The DSM-IV Hyperactive-Impulsive, DSM-IV Inattentive, and the Conner's GI-Restless-Impulsive. The following CPRS-R:L subtests were combined for the internalizing scale: Anxious/Shy, Social Problems, and Perfectionism. As recommended (Beebe, 2006), the Psychosomatic symptom subscale was not included in the Internalizing score, given that somatic complaints are often reported not only by children with SDB, but also children with many other medical conditions, suggesting these items may inflate true levels of emotional disturbance. For the externalizing scale, the Oppositional and Emotional-Lability scores were combined.

\section{Data Analysis Plan}

Comparisons of sleep parameters and demographic factors before and after AT surgery were presented previously (Chervin et al., 2006). For the present data, analyses of variance (ANOVA) were computed to examine differences between the control group and AT children divided by the presence of OSA (i.e., AT/OSA - and AT/OSA +). The two AT groups were compared with the controls by means of planned contrasts (i.e., AT/OSA + vs. controls and AT/OSA$v s$. controls). In these analyses, the overall "group" effect represents the combined effect of both contrasts (i.e., the overall AT vs. control comparison). We report Cohen's d statistic for all comparisons that were significant as recommended (Beebe, 2006) as a measure of the strength of the statistical relationship. Effect sizes close to 0.5 are considered moderate, with 0.8 considered large (Cohen, 1988). Histograms of residuals of the analyses suggested that assumptions of normality were valid for all variables. Because this study was largely exploratory in nature, an alpha level of .05 was applied in assessing the significance of all group comparisons.

\section{RESULTS}

The adjusted means, standard deviations, and statistics for the neuropsychological domains for the AT/OSA+,
AT/OSA - and control groups are listed in Table 2. Significant group effects denoting lower performance in AT children compared with controls for measures related to visual spatial ability, arithmetic academic achievement, one test of visual delayed recall, and short-term attention/ working memory were observed. Planned comparisons demonstrated relatively larger and more consistently significant differences between the AT/OSA - and control groups, as compared with AT/OSA + versus control contrasts. Trends were also noted for several verbal academic achievement scales and for a test of sustained attention, in each case reflecting lowered performance for the AT/OSA - group as compared with controls.

On parental ratings of hyperactive behavior, significantly higher concerns were noted by parents of both AT groups as compared with the parents of controls. However, internalizing and externalizing domains of behavior yielded mixed findings. Although mean differences were small and all mean scores within normal limits, when compared with controls, parents of children in the AT/OSA - group reported significantly greater numbers of externalizing symptoms, while parents of AT/OSA + children emphasized internalizing problems.

Although the comparisons between the control group and each of the two AT groups were of primary interest in this study, secondary analyses contrasting the AT/OSA + and AT/OSA - groups also were performed. For the demographic and sleep-related variables, the two AT groups were found not to differ on age, education, SES, MSLT, or the PSQ Sleepiness score, though, as expected, more difficulties were evident for AT/OSA + children on OAI $(p<.001)$ and PSQ Snoring $(p<.001)$. Across the neuropsychological measures, the Matrices subtest was significantly lower in the AT/OSA - as compared with AT/OSA + group $(p<$ $.01)$. No differences were evident between the AT groups on the Conner's parent ratings.

\section{DISCUSSION}

The few studies that have evaluated neuropsychological functioning in children scheduled for AT have been inconclusive as to whether these children are at substantial risk for both cognitive and behavioral difficulties. In this study, both groups of AT children scored lower than controls on a measure associated with visual spatial problem solving and on a measure of visual delayed recall that requires memory for sequences of visual spatial information within a dot array. The two groups also had lower tests scores as compared with controls on a measure of arithmetic academic achievement that calls for knowledge of mathematical concepts and problem solving.

Our primary hypothesis, neuropsychological difficulties in children with AT would be increased as compared with controls, was confirmed, although the hypothesized detrimental effects on executive functioning and sustained attention were not found. In addition, our data did not support our secondary hypothesis that deficits in AT patients with 
Table 2. Means and standard deviations for behavioral and cognitive test scores

\begin{tabular}{|c|c|c|c|c|c|c|}
\hline \multirow[b]{2}{*}{ Neuropsychological domains } & \multicolumn{4}{|c|}{ Group effect } & \multicolumn{2}{|c|}{$\begin{array}{l}\text { Effect sizes and } p \text { values } \\
\text { for control comparisons }\end{array}$} \\
\hline & $\begin{array}{l}\text { AT/OSA+ } \\
(n=40)\end{array}$ & $\begin{array}{l}\mathrm{AT} / \mathrm{OSA}- \\
(n=38)\end{array}$ & $\begin{array}{l}\text { Controls } \\
(n=26)\end{array}$ & $F$ & $\mathrm{AT} / \mathrm{OSA}+$ & AT/OSA- \\
\hline \multicolumn{7}{|l|}{ Verbal Ability ${ }^{\mathrm{a}}$} \\
\hline Vocabulary & $\begin{array}{c}52.56 \\
(11.01)^{b}\end{array}$ & $\begin{array}{c}52.08 \\
(10.39)\end{array}$ & $\begin{array}{c}55.76 \\
(11.38)\end{array}$ & 0.95 & & \\
\hline Similarities & $\begin{array}{l}58.72 \\
(9.35)\end{array}$ & $\begin{array}{l}56.54 \\
(9.26)\end{array}$ & $\begin{array}{l}59.44 \\
(8.62)\end{array}$ & 0.90 & & \\
\hline \multicolumn{7}{|l|}{ Visual Spatial Ability ${ }^{a}$} \\
\hline Block Design & $\begin{array}{c}52.10 \\
(12.14)\end{array}$ & $\begin{array}{l}51.57 \\
(9.57)\end{array}$ & $\begin{array}{c}58.56 \\
(10.88)\end{array}$ & $3.57 *$ & $.55^{*}$ & $.69 * *$ \\
\hline Matrices & $\begin{array}{l}54.85 \\
(8.61)\end{array}$ & $\begin{array}{l}49.35 \\
(9.06)\end{array}$ & $\begin{array}{l}56.28 \\
(8.43)\end{array}$ & $5.83 * *$ & & $.85^{* *}$ \\
\hline \multicolumn{7}{|l|}{ Academic Ability ${ }^{\mathrm{c}}$} \\
\hline Spelling & $\begin{array}{c}104.80 \\
(16.09)\end{array}$ & $\begin{array}{c}98.45 \\
(13.83)\end{array}$ & $\begin{array}{c}106.69 \\
(16.19)\end{array}$ & $2.71^{\mathrm{d}}$ & & $.56^{*}$ \\
\hline Reading Comprehension & $\begin{array}{l}104.89 \\
(15.41)\end{array}$ & $\begin{array}{l}100.79 \\
(15.00)\end{array}$ & $\begin{array}{l}110.88 \\
(19.97)\end{array}$ & $2.61^{\mathrm{d}}$ & & $.59 *$ \\
\hline Listening Comprehension & $\begin{array}{l}112.23 \\
(16.91)\end{array}$ & $\begin{array}{l}107.10 \\
(13.98)\end{array}$ & $\begin{array}{l}115.92 \\
(16.62)\end{array}$ & $2.52^{\mathrm{d}}$ & & $.58 *$ \\
\hline Reading & $\begin{array}{l}105.33 \\
(14.65)\end{array}$ & $\begin{array}{l}101.37 \\
(15.01)\end{array}$ & $\begin{array}{l}108.00 \\
(17.23)\end{array}$ & 1.50 & & \\
\hline Oral Expression & $\begin{array}{l}122.15 \\
(15.37)\end{array}$ & $\begin{array}{l}116.24 \\
(10.83)\end{array}$ & $\begin{array}{l}118.00 \\
(10.81)\end{array}$ & 2.17 & & \\
\hline Mathematics & $\begin{array}{l}106.60 \\
(14.87)\end{array}$ & $\begin{array}{r}102.66 \\
(9.53)\end{array}$ & $\begin{array}{l}115.23 \\
(15.83)\end{array}$ & $6.85 * *$ & $.57 * *$ & $1.01 * * *$ \\
\hline Number Operations & $\begin{array}{l}102.26 \\
(16.38)\end{array}$ & $\begin{array}{c}96.00 \\
(15.00)\end{array}$ & $\begin{array}{l}105.38 \\
(15.60)\end{array}$ & $3.01 *$ & & $.62 *$ \\
\hline \multicolumn{7}{|l|}{ Verbal Learning ${ }^{\mathrm{e}}$} \\
\hline Word List Learning & $\begin{array}{l}10.48 \\
(3.67)\end{array}$ & $\begin{array}{c}9.92 \\
(3.37)\end{array}$ & $\begin{array}{l}11.00 \\
(3.16)\end{array}$ & 0.77 & & \\
\hline Story Learning & $\begin{array}{l}11.10 \\
(2.96)\end{array}$ & $\begin{array}{l}10.03 \\
(3.47)\end{array}$ & $\begin{array}{l}10.60 \\
(3.08)\end{array}$ & 1.11 & & \\
\hline \multicolumn{7}{|l|}{ Verbal Delayed Recalle } \\
\hline Word Recall & $\begin{array}{l}10.67 \\
(3.66)\end{array}$ & $\begin{array}{c}9.92 \\
(3.66)\end{array}$ & $\begin{array}{l}11.31 \\
(3.43)\end{array}$ & 1.18 & & \\
\hline Story Recall & $\begin{array}{l}10.55 \\
(3.41)\end{array}$ & $\begin{array}{l}10.16 \\
(3.90)\end{array}$ & $\begin{array}{l}10.42 \\
(3.30)\end{array}$ & 0.12 & & \\
\hline \multicolumn{7}{|l|}{ Visual Learning ${ }^{\mathrm{e}}$} \\
\hline Dot Learning & $\begin{array}{l}10.80 \\
(3.45)\end{array}$ & $\begin{array}{l}10.21 \\
(3.10)\end{array}$ & $\begin{array}{l}10.88 \\
(3.14)\end{array}$ & 0.45 & & \\
\hline Face Learning & $\begin{array}{c}9.85 \\
(2.46)\end{array}$ & $\begin{array}{c}9.84 \\
(2.88)\end{array}$ & $\begin{array}{l}11.08 \\
(3.31)\end{array}$ & 1.67 & & \\
\hline \multicolumn{7}{|l|}{ Visual Delayed Recalle } \\
\hline Dot Recall & $\begin{array}{l}11.05 \\
(2.78)\end{array}$ & $\begin{array}{l}11.05 \\
(2.69)\end{array}$ & $\begin{array}{l}12.58 \\
(1.39)\end{array}$ & $3.71 *$ & $.65^{*}$ & $.67 *$ \\
\hline Face Recall & $\begin{array}{l}10.22 \\
(2.90)\end{array}$ & $\begin{array}{c}9.74 \\
(2.89)\end{array}$ & $\begin{array}{l}11.12 \\
(2.93)\end{array}$ & 1.75 & & \\
\hline \multicolumn{7}{|l|}{ Short-Term Attention ${ }^{\mathrm{e}}$} \\
\hline Numbers & $\begin{array}{l}10.65 \\
(2.37)\end{array}$ & $\begin{array}{c}9.62 \\
(3.30)\end{array}$ & $\begin{array}{l}11.46 \\
(2.70)\end{array}$ & $3.37 *$ & & $.59 * *$ \\
\hline Sequences & $\begin{array}{l}10.15 \\
(3.14)\end{array}$ & $\begin{array}{c}8.85 \\
(3.38)\end{array}$ & $\begin{array}{l}11.04 \\
(3.57)\end{array}$ & $3.40 *$ & & $.63 * *$ \\
\hline \multicolumn{7}{|l|}{ Sustained Attention ${ }^{\mathrm{f}}$} \\
\hline Inattention (FSAQ) & $\begin{array}{c}79.42 \\
(22.03)\end{array}$ & $\begin{array}{c}75.60 \\
(21.04)\end{array}$ & $\begin{array}{c}88.32 \\
(21.44)\end{array}$ & $2.67^{\mathrm{b}}$ & & $.60 *$ \\
\hline
\end{tabular}


Table 2. Continued

\begin{tabular}{|c|c|c|c|c|c|c|}
\hline \multirow[b]{2}{*}{ Neuropsychological domains } & \multicolumn{4}{|c|}{ Group effect } & \multicolumn{2}{|c|}{$\begin{array}{l}\text { Effect sizes and } p \text { values } \\
\text { for control comparisons }\end{array}$} \\
\hline & $\begin{array}{c}\text { AT/OSA }+ \\
(n=40)\end{array}$ & $\begin{array}{l}\text { AT/OSA- } \\
(n=38)\end{array}$ & $\begin{array}{l}\text { Controls } \\
(n=26)\end{array}$ & $F$ & $\mathrm{AT} / \mathrm{OSA}+$ & $\mathrm{AT} / \mathrm{OSA}-$ \\
\hline \multicolumn{7}{|l|}{ Sustained Attention $^{\mathrm{f}}$ (continued) } \\
\hline Impulsivity (FSRCQ) & $\begin{array}{l}101.78 \\
(13.57)\end{array}$ & $\begin{array}{c}93.60 \\
(21.15)\end{array}$ & $\begin{array}{c}94.80 \\
(22.44)\end{array}$ & 2.05 & & \\
\hline \multicolumn{7}{|l|}{ Executive Functioning } \\
\hline Category Test & $\begin{array}{c}53.78 \\
(12.80)\end{array}$ & $\begin{array}{c}55.13 \\
(11.12)\end{array}$ & $\begin{array}{l}56.38 \\
(7.79)\end{array}$ & 0.44 & & \\
\hline \multicolumn{7}{|l|}{ Fine Motor Control } \\
\hline Purdue Pegboard (Both Hands) & $\begin{array}{c}8.28 \\
(2.84)\end{array}$ & $\begin{array}{c}8.37 \\
(2.02)\end{array}$ & $\begin{array}{c}9.12 \\
(2.60)\end{array}$ & 1.00 & & \\
\hline \multicolumn{7}{|l|}{ Behavior $^{\mathrm{g}}$} \\
\hline Hyperactivity & $\begin{array}{l}50.86 \\
(8.68)\end{array}$ & $\begin{array}{l}52.40 \\
(8.68)\end{array}$ & $\begin{array}{l}44.86 \\
(4.84)\end{array}$ & $4.99 * *$ & $.81 * *$ & $.74 * *$ \\
\hline Externalizing & $\begin{array}{l}49.79 \\
(9.65)\end{array}$ & $\begin{array}{c}52.97 \\
(11.89)\end{array}$ & $\begin{array}{l}45.43 \\
(4.93)\end{array}$ & $4.68 * *$ & & $.83 * *$ \\
\hline Internalizing & $\begin{array}{l}50.31 \\
(7.41)\end{array}$ & $\begin{array}{c}52.37 \\
(13.06)\end{array}$ & $\begin{array}{l}45.57 \\
(6.35)\end{array}$ & $3.74 * *$ & $.68 * *$ & \\
\hline
\end{tabular}

${ }^{a}$ Wechsler Abbreviated Scale of Intelligence (WASI).

${ }^{b}$ Numbers in parentheses represent standard deviations.

${ }^{\mathrm{c}}$ Wechsler Individualized Achievement Test (WIAT).

${ }^{\mathrm{d}}$ Trend for significance at $p<.08$ or better.

eChildren's Memory Test (CMS).

${ }^{\mathrm{f}}$ Integrated Visual and Auditory Continuous Performance Test (IVA), Full Scale Attention Quotient (FSAQ) and Full Scale Response Control Quotient (FSRCQ).

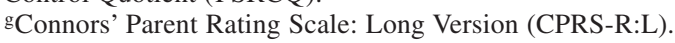

$* p<.05$.

$* * p<.01$.

$* * * p<.001$.

polysomnographic evidence of OSA would be increased as compared with those without polysomnographic evidence of OSA. Of interest, across the three tests in which both AT groups differed from controls (Block Design, Mathematics, Dot Recall), the AT/OSA - group demonstrated more robust differences from controls than those demonstrated by the AT/OSA + group. The AT/OSA - group, and not the AT/OSA + group, also scored significantly lower than controls on three of subtests of the WIAT related to reading and verbal-based academic achievement, two measures of shortterm attention and working memory, and on a subscale from a computerized vigilance test that reflects a child's ability to sustain attention over time. Most effect sizes for differences between the AT groups and the control group were at least moderate in degree. No differences between AT and control groups were evident on a computerized measures of impulsivity, a test of executive functioning, and on verbalbased measures of general aptitude and memory.

Our analyses did not reveal a clear explanation for why, as compared with controls, AT/OSA - children more consistently showed neurobehavioral symptoms than did AT/OSA+ children. Age did not appear to underlie these differences. The AT/OSA - group was somewhat older than the AT/OSA+ group, allowing more opportunity for adverse effects of SDB to accumulate over time, however, covarying age in the analy- ses did not appreciably change the findings. Another possible explanation considered for the observed differences was that the reasons parents first brought their children to their pediatrician or otolaryngologist who then referred the child for surgery were different across the two AT groups and that these underlying reasons somehow contributed to the poorer outcomes in the AT/OSA - group. Although this specific information was not collected in this study, a post hoc review of the medical referral forms received by the surgeons did not reveal any differences. It also is possible that the AT/OSA - group may have had additional problems or sickness complaints that contributed to sleep problems, leading to more consistent cognitive disruption in this group. For example, recurrent throat infections - with attendant missed days of school, immune system challenges, fever, or other adverse impacts - could underlie the neurobehavioral morbidity in the AT/OSA - children. If so, the tendency for recurrent infection or even other not yet apparent environmental or situational factors disrupting sleep could explain our results. However, collection of the data from parents that would have allowed examination of these possibilities was beyond the scope of this study.

After considering the possible explanations above, a reasonable speculation is that current standard polysomnographic measures are insensitive to some important 
pathophysiological feature of sleep or breathing that is more prominent in AT/OSA - subjects than the AT/OSA+ subjects. For example, several studies (Beebe et al., 2004; Chervin et al., 2006; Gottlieb et al., 2004; O'Brien et al., 2003; Rosen et al., 2004) and the recent review by Beebe (2006) have all pointed out that the parental reports of snoring and sleepiness may be in and of themselves more powerful predictors of cognitive morbidity in children than currently used polysomnographic measurements. As Chervin and colleagues (2006) point out, this may suggest that current polysomnographic measures may not be as sensitive as parental observations of everyday functioning for the characterization of the relatively mild level of SDB usually observed in children presenting to otolaryngologists for consideration of AT. Newer, more sophisticated analytical techniques may hold promise, however, in identifying what specific features make the AT/OSA - group more vulnerable (Chervin et al., 2004; Lopes et al., 2005; O'Brien et al., 2004b). To better understand what contributed to the poorer presurgical performance of the AT/OSAchildren when comparing morbidity in AT/OSA+ and AT/OSA - children, potential differences between the AT groups in specialized sleep measures or in distinct symptom presentation may need to be considered.

Consistent with our general results, difficulties in aspects of visuospatial ability and visual attention associated with SDB in children have been noted in several studies (Friedman et al., 2003; Archbold et al., 2004; Beebe et al., 2004). However, our specific significant findings on the Wechsler scales and the Children's Memory Scale have not been observed by several other groups using these measures (Archbold et al., 2004; Beebe et al., 2004; Blunden et al., 2005; Owens et al., 2000). Differences between the methodologies in these studies and ours, including control comparisons and sample size, could contribute to these differential findings (Beebe, 2006). For example, Archbold and colleagues (2004; an earlier study from our group) and Owens and colleagues (2000) included small, relatively heterogeneous samples of children with SDB and made comparisons to published normative data. Blunden and colleagues (2005) did not use polysomnographic measures of SDB and their control group was composed of children awaiting "sick" visits with private practice physicians, whereas we used polysomnographic measures and our control group was composed of children awaiting elective surgery or receiving surgical outpatient care with no planned procedure. Beebe et al. (2004) compared three smaller groups of children differing on polysomnographically characterized levels of OSA to community-based volunteers using a different approach from our polysomographic classification of both controls and patients.

Although the brain mechanisms underlying the results we report are unclear and may involve systems that are not strictly localized, the predominant findings of lowered visualbased skills could be interpreted as suggesting that right cerebral functions, in comparison to left cerebral functions, are more susceptible to sleep disturbances in children sched- uled for AT. Aspects of attention and arithmetic functioning (noted to be susceptible to disruption in this study) also have been tied to right hemisphere functioning (Grunau and Low, 1987; Landau and Gross-Tsur, 1999; Troup et al., 1983; Voeller, 1986). Thus, our results are consistent with other studies that have suggested that right hemisphere-related areas mediating problem solving and close attention during visual-spatial processing may be particularly susceptible to dysfunction when sleep is chronically disrupted (Hopkins and Haaland, 2004; Kales et al., 1985; Naismith et al., 2004). Right hemisphere functions also have been found to be particularly vulnerable to decline in other conditions associated with hypoxia and developmental neurological conditions (Gale and Hopkins, 2004; Sotaniemi, 1980; Stiers et al., 2001). On the other hand, further research is clearly necessary, as several studies using other visual-based subtests different from ours, such as those from the Differential Abilities Test (Lewin et al., 2002; O'Brien et al., 2004a) or the NEPSY (O'Brien et al., 2004a), have found no clear evidence of such impairment.

Our finding of significantly lower scores for the AT/OSAgroup on measures of short-term attention and sustained attention suggests that our previous finding of differences between AT and control children on a summary measure of overall attention (Chervin et al., 2006) may be primarily related to the AT/OSA - group's lower performance and appears to involve multiple aspects of attention and working memory. Attention problems often have been cited as a common feature associated with SDB, though, for the most part, these findings have been restricted to sustained attention (i.e., errors of omission) and not to short-term attention and working memory (Beebe, 2006; O'Brien et al., 2004a; Owens et al., 2000). This difference may relate to the possibility of more pervasive cognitive difficulties in the AT/OSA - group, the smaller sample sizes used in other studies yielding less power, or perhaps the more sensitive nature of the working memory tasks included in this study.

Even though measures of executive functioning often have been posited as being particularly susceptible to decline in SDB, our data did not reflect such on the Category Test, a measure of conceptual leaning and executive functioning. This test, however, does not require a significant component of visual-motor processing, and our results are similar to other reports of no deficits in OSA subjects on the related Wisconsin Card Sorting Test (Beebe et al., 2004; Naismith et al., 2004; Salorio et al., 2002). As mentioned above, it is possible that sleep disturbance may be more specific in affecting aspects of the executive system that control more complex features of attention and problem solving, such as working memory or when visual-motor integration demands are high (e.g., WASI Block Design and Matrices subtests).

Children awaiting tonsillectomy or with evidence of SDB often have been noted to have lowered parent or teacher reports of school performance, although have not performed below expectation on standardized tests of academic ability (Beebe, 2006; Beebe et al., 2004; Chervin et al., 2003; Gozal and Pope, 2001; Urschitz et al., 2003). 
In our study, the AT/OSA - children did score lower than controls on several academic test measures and both AT groups scored below controls on a test of arithmetic calculations. It is possible that the greater sensitivity to school disruption seen on our standardized test measures may be explained by the somewhat older age of children in our study and/or the more extensive impairment evident because the AT/OSA - group was considered separately; although we did not have more generalized school-related reports available for comparison.

Consistent with past concerns over behavioral control (c.f., Beebe, 2006), in this study, parents of both groups of AT-referred children were more likely than parents of controls to report symptoms of hyperactivity. However, none of the mean scores on any of the computed scales fell in the clinically significant range $(>65 \mathrm{~T}$ or $>1.5 S D$ from a mean of 50). In addition, although differences among the groups on the behavior scales are relativity modest, the children with polysomnographically confirmed SDB had higher ratings for internalizing behaviors as compared with controls, while the AT/OSA - group was higher in externalizing behaviors. Given the prevalence of suspicion among clinicians, parents, and the media that tonsillectomies may improve behavioral problems, the higher parental problem ratings for the AT children in both emotional and sleeprelated questionnaires could reflect a response bias by the AT parents. Past data on behavioral findings related to internalizing and externalizing symptoms in children with SDB have been mixed (Beebe, 2006), and the differential behavior problems of our two AT groups support the need for further research.

This study has limitations due to the cross sectional nature of the data collection; data from a one year follow-up is currently being analyzed. In addition, our control group, although recruited from the same hospital setting and within the age range of the AT children, was slightly older than the AT groups. It is interesting to note that the AT/OSA - group, which scored lowest on several of the cognitive measures, was not significantly different from the control group in terms of age or education (or polysomnographic measures). Our results, however, emphasize the importance of evaluating several sleep-related issues in an attempt to better understand the extent and etiology of more subtle pathophysiological changes that may occur in childhood SDB. These include the role of sleepiness, snoring, and other behavioral manifestations of sleep disturbance, the potential utility of newer and more sensitive approaches to polysomnographic assessment, and developmental changes in symptoms.

\section{ACKNOWLEDGMENTS}

There are no financial or other relationships that could be interpreted as a conflict of interest affecting this manuscript. The work reported in this manuscript was supported by the National Institutes of Health (1R01 HD38461), "Behavioral Effect of Obstructive Sleep Apnea in Children."

\section{REFERENCES}

Ali, N.J., Pitson, D., \& Stradling, J.R. (1996). Sleep disordered breathing: Effects of adenotonsillectomy on behaviour and psychological functioning. European Journal of Pediatrics, 155, $56-62$.

Archbold, K.H., Giordani, B., Ruzicka, D., \& Chervin, R.D. (2004). Cognitive executive dysfunction in children with mild sleep apnea. Biological Research for Nursing, 5, 168-176.

Avior, G., Fishman, G., Leor, A., Sivan, Y., Kaysar, N., \& Derowe, A. (2004). The effect of tonsillectomy and adenoidectomy on inattention and impulsivity as measured by the Test of Variables of Attention (TOVA) in children with obstructive sleep apnea syndrome. Otolaryngology-Head and Neck Surgery, 368 , 367-371.

Bartlett, D., Rae, C., Thompson, C., Byth, K., Joffe, D., Enright, T., \& Grunstei, R. (2004). Hippocampal area metabolites relate to severity and cognitive function in OSA. Sleep Medicine, 5 , 593-596.

Beebe, D.W. (2006). Neurobehavioral morbidity associated with disordered breathing during sleep in children: A comprehensive review. Sleep, 29, 1115-1134.

Beebe, D.W. \& Gozal, D. (2002). Obstructive sleep apnea and the prefrontal cortex: Toward a comprehensive model linking nocturnal upper airway obstruction to daytime cognitive and behavioral deficits. Journal of Sleep Research, 11, 1-16.

Beebe, D.W., Wells, C.T., Jeffries, J., Chini, B., Kalra, M., \& Amin, R. (2004). Neuropsychological effects of pediatric obstructive sleep apnea. Journal of the International Neuropsychological Society, 10, 962-975.

Blunden, S., Lushington, K., Lorenzen, B., Martin, J., \& Kennedy, D. (2005). Neuropsychological and psychosocial functioning children with a history of snoring or behavioral sleep problems. Journal of Pediatrics, 146, 780-786.

Boll, T.J. (1993). Children's Category Test. San Antonio, TX: The Psychological Corporation.

Carskadon, M.A., Dement, W.C., Mitler, M.M., Roth, T., Westrook, P.R., \& Keenan, S. (1986). Guidelines for the multiple sleep latency test (MSLT): A standard measure of sleepiness. Sleep, 9, 519-524.

Chervin, R.D., Burns, J.W., Subotic, N.S., Roussi, C., Thelen, B., \& Ruzicka, D.L (2004). Method for detection of respiratory cycle-related EEG changes in sleep-disordered breathing. Sleep, 27, 110-115.

Chervin, R.D., Clarke, D.F., Huffman, J.L., Szymanski, E., Ruzicka, D.L., Miller, V., Nettles, A.L., Sowers, M.R., \& Giordani, B. (2003). School performance, race, and other correlates of sleep-disordered breathing in children. Sleep Medicine, 4, 21-27.

Chervin, R.D., Hedger, K.M., Dillon, J.E., \& Pituch, K.J. (2000). Pediatric sleep questionnaire (PSQ): Validity and reliability of scale for sleep-disordered breathing, snoring, sleepiness and behavioral problems. Sleep Medicine, 1, 21-32.

Chervin, R.D., Ruzicka, D.L., Giordani, B.J., Weatherly, R.A., Dillon, J.E., Hodges, E.K., Marcus, C.L., \& Guire, K.E. (2006). Sleep-disordered breathing, behavior, and cognition in children before and after adenotonsillectomy. Pediatrics, 117, e769-e778.

Chervin, R.D., Weatherly, R.A., Garetz, S.L., Ruzicka, D.L., Giordani, B.J., Hodges, E.K., Dillon, J.E., \& Guire, K.E. (2007). Pediatric sleep questionnaire: Prediction of sleep apnea and outcomes. Archives of Otolaryngology Head and Neck Surgery, 133, 216-222. 
Cohen, C.K. (1988). Statistical Power Analysis for the Behavioral Sciences (2nd ed.). Hillsdale, NJ: Lawrence Erlbaum Associates.

Cohen, M.J. (1997). Children's Memory Scale. San Antonio, TX: The Psychological Corporation.

Conners, C.K. (1997). Conners' Rating Scales-Revised: User's manual. North Tonawanda, NY: Multi-Health Systems, Inc.

Emancipator, J.L., Storfer-Isser, A., Taylor, H.G., Rosen, C.L., Kirchner, H.L., Johnson, N.L., Zambito, A.M., \& Redline, S. (2006). Variation of cognition and achievement with sleepdisordered breathing in full-term and preterm children. Archives of Pediatrics and Adolescent Medicine, 160, 203-210.

Friedman, B., Hendeles-Amitai, A., Kosminsky, E., Lieberman, A., Friger, M., Tarasiuk, A., \& Tal, A. (2003). Adenotonsillectomy improves neurocognitive functioning in children with obstructive sleep apnea syndrome. Sleep, 26, 999-1005.

Gale, S.D. \& Hopkins, R.O. (2004). Effects of hypoxia on the brain: Neuroimaging and neuropsychological findings following carbon monoxide poisoning and obstructive sleep apnea. Journal of the International Neuropsychological Society, 10, 60-71.

Gottlieb, D.J., Chase, C., Vezina, R.M., Heeren, T.C., Corwin, M.J., Auerbach, S.E., Weese-Mayer, D.E., \& Lesko, S.M. (2004). Sleep-disordered breathing symptoms are associated with poorer cognitive function in 5-year-old children. Journal of Pediatrics, 145, 458-464.

Gottlieb, D.J., Vezina, R.M., Chase, C., Lesko, S.M., Heeren, T.C., Weese-Mayer, D.E., Auerbach, S.H., \& Corsin, M.J. (2003). Symptoms of sleep-disordered breathing in 5-year-old children are associated with sleepiness and problem behaviors. Pediatrics, 112, 870-877.

Gozal, D. \& Pope, D. (2001). Snoring during early childhood and academic performance at ages thirteen to fourteen years. Pediatrics, 107, 1394-1399.

Grunau, R.V. \& Low, M.D. (1987). Cognitive and task-related EEG correlates of arithmetic performance in adolescents. Journal of Clinical \& Experimental Neuropsychology, 9, 563-574.

Halbower, A.C., Degaonkar, M., Barker, P.B., Earley, C.J., Marcus, C.L., Smith, P.L., Prahme, M.C., \& Mahone, E.M. (2006). Childhood obstructive sleep apnea associates with neuropsychological deficits and neuronal brain injury. Pubic Library of Science Medicine, 3, 1391-1402.

Hibbert, J. (1981). The occurrence of adenoidal signs and symptoms in normal children. Clinical Otolaryngology, 6, 97-100.

Hopkins, R.O. \& Haaland, K.Y. (2004). Neuropsychological and neuropathological effects of anoxic or ischemic induced brain injury. Journal of the International Neuropsychological Society, 10, 957-961.

Kaemingk, K.L., Pasvogel, A.E., Goodwin, J.L., Mulvaney, S.A., Martinez, F., Enright, P.L., Rosen, G.M., Morgan, W.L., Fregosi, R.F., \& Quan, S.F. (2003). Learning in children and sleepdisordered breathing: Findings of the Tucson Children's Assessment of Sleep Apnea (TuCASA) prospective cohort study. Journal of the International Neuropsychological Society, 9, 1016-1026.

Kales, A., Caldwell, A.B., Cadieux, R.J., Vela-Bueno, A., Ruch, L.G., \& Mayes, S.D. (1985). Severe obstructive sleep apneaII: Associated psychopathology and psychosocial consequences. Journal of Chronic Diseases, 38, 427-434.

Kennedy, J.D., Blunden, S., Hirte, C., Parsons, D.W., Martin, A.J., Crowe, E., Williams, D., Pamula, Y., \& Lushington, K. (2004). Reduced neurocognition in children who snore. Pediatric Pulmonology, 37, 330-337.
Landau, Y.E. \& Gross-Tsur, V. (1999). Attention deficit disorder: Attentional characteristics of developmental right hemisphere syndrome. Harefuah, 136, 596-599.

Lewin, D.S., Rosen, R.C., England, S.J., \& Dahl, R.E. (2002). Preliminary evidence of behavioral and cognitive sequelae of obstructive sleep apnea in children. Sleep Medicine, 3, 5-13.

Lopes, M.A., Rosa, A., Roizenblatt, S., Guilleminault, C., Passarelli, C., Tufik, S., \& Poyares, D. (2005). Cyclic alternating pattern in peripubertal children. Sleep, 28, 215-219.

Marcus, C.L. \& Loughlin, G.M. (1996). Obstructive sleep apnea in children. Seminars in Pediatric Neurology, 3, 23-28.

Marcus, C.L., Omlin, K.J., Basinki, D.J., Bailey, S.L., Rachal, A.B., Von Pechmann, W.S., Keens, T.G., \& Ward, S.L. (1992). Normal polysomnographic values for children and adolescents. American Review of Respiratory Disease, 146(Pt. 1), $1235-1239$.

Mitchell, R.B. \& Kelly, J. (2005). Child behavior after adenotonsillectomy for obstructive sleep apnea syndrome. The Laryngoscope, 115, 2051-2055.

Montgomery-Downs, H.E., Crabtree, V.M., \& Gozal, D. (2005). Cognition, sleep and respiration in at-risk children treated for obstructive sleep apnoea. European Respiratory Journal, 25, 336-342.

Morrell, M., McRobbie, D., Quest, R., Cummin, A., Ghiassi, R., \& Corfield, D. (2004). Changes in brain morphology associated with obstructive sleep apnea. Sleep Medicine, 4, 451-454.

Naismith, S., Winter, V., Gotsopoulos, H., Hickie, I., \& Cistulli, P. (2004). Neurobehavioral functioning in obstructive sleep apnea: Differential effects of sleep quality, hypoxemia and subjective sleepiness. Journal of Clinical and Experimental Neuropsychology, 26, 43-54.

O’Brien, L.M., Holbrook, C.R., Mervis, C.B., Klaus, C.J., Bruner, J.L., Raffield, T.J., Rutherford, J., Mehl, R.C., Wang, M., Tuell, A., Hume, B.C., \& Gozal, D. (2003). Sleep and neurobehavioral characteristics of 5- to 7-year-old children with parentally reported symptoms of attention-deficit/hyperactivity disorder. Pediatrics, 111, 554.

O’Brien, L.M., Mervis, C.B., Holbrook, C.R., Bruner, J.L., Smith, N.H., McNally, N., McClimment, M.C., \& Gozal, D. (2004a). Neurobehavioral correlates of sleep-disordered breathing in children. Journal of Sleep Research, 13, 165-172.

O’Brien, L.M., Tauman, R., \& Gozal, D. (2004b). Sleep pressure correlates of cognitive and behavioral morbidity in snoring children. Sleep, 27, 279-282.

Owens, J., Spirito, A., Marcotte, A.C., McGuinn, M., \& Berkelhammer, L. (2000). Neuropsychological and behavioral correlates of obstructive sleep apnea syndrome in children: A preliminary study. Sleep and Breathing, 4, 67-68.

Rechtschaffen, A. \& Kales, A. (1968). A Manual of Standardized Terminology, Techniques and Scoring System for Sleep Stages Of Human Subjects. Los Angeles: Brain Information Service/ Brain Research Institute, UCLA.

Rosen, C.L., Storfer-Isser, A., Taylor, H.G., Kirchner, H.L., Emancipator, J.L., \& Redline, S. (2004). Increased behavioral morbidity in school-aged children with sleep-disordered breathing. Pediatrics, 114, 44-49.

Rosenfeld, R.M. \& Green, R.P. (1990). Tonsillectomy, and adenoidectomy: Changing trends. Annals of Otology, Rhinology, and Laryngology, 99, 187-191.

Salorio, C.F., Whitel, D.A., Piccirillo, J., Duntley, S.P., \& Uhles, M.L. (2002). Learning, memory, and executive control in individuals with obstructive sleep apnea syndrome. Journal of Clinical and Experimental Neuropsychology, 24, 93-100. 
Sanford, J.A. \& Turner, A. (1994). Integrated Visual and Auditory Continuous Performance Test Manual. Richmond, VA: BrainTrain.

Sotaniemi, K.A. (1980). Brain damage and neurological outcome after open-heart surgery. Journal of Neurology, Neurosurgery, and Psychiatry, 43, 127-135.

Stiers, P., van den Hout, B.M., Haers, M., Vanderkelen, R., de Vries, L.S., van Nieuwenhuizen, O., \& Vandenbussche, E. (2001). The variety of visual perceptual impairments in preschool children with perinatal brain damage. Brain and Development, 23, 333-348.

Stradling, J.R., Thomas, G., Warley, A.H., Williams, P., \& Freeland, A. (1990). Effect of adenotonsillectomy on nocturnal hypoxaemia, sleep disturbance and symptoms in snoring children. Lancet, 335, 249-253.

The Psychological Corporation. (1992). Wechsler Individual Achievement Test. San Antonio, TX: The Psychological Corporation.

The Psychological Corporation. (1999). Wechsler Abbreviated Scale of Intelligence. San Antonio, TX: The Psychological Corporation.

Tiffin, J. (1968). Purdue Pegboard Examiner's Manual. Rosemont, IL: London House.
Troup, G.A, Bradshaw, J.L., \& Nettleton, N.C. (1983). The lateralization of arithmetic and number processing: A review. International Journal of Neuroscience, 19, 231-241.

Urschitz, M.S., Guenther, A., Eggebrecht, E., Wolff, J., UrschitzDuprat, P.M., Schlaud, M., \& Pets, C.F. (2003). Snoring, intermittent hypoxia and academic performance in primary school children. American Journal of Respiratory Critical Care Medicine, 168, 464-468.

Voeller, K.K. (1986). Right-hemisphere deficit syndrome in children. American Journal of Psychiatry, 143, 1004-1009.

Weatherly, R.A., Mai, E.F., Ruzicka, D.L., \& Chervin, R.D. (2003). Identification and evaluation of obstructive sleep apnea prior to adenotonsillectomy in children: A survey of practice patterns. Sleep Medicine, 4, 297-307.

Weatherly, R.A., Ruzicka, D.L., Marriott, D.J., \& Chervin, R.D. (2004). Polysomnography in children scheduled for adenotonsillectomy. Otolaryngology-Head and Neck Surgery, 131, 727-731.

Zoccoli, G., Walker, A.M., Lenzi, P., \& Franzini, C. (2002). The cerebral circulation during sleep: Regulation mechanisms and functional implications. Sleep Medicine Reviews, 6, 443. 